\title{
COMPARISON OF THE EFFECT OF PTEROCARPUS MARSUPIUM WITH PIOGLITAZONE IN DEXAMETHASONE-INDUCED INSULIN RESISTANCE
}

\author{
KOYAGURA NARENDAR ${ }^{1 *}$, I M NAGENDRA NAYAK ${ }^{2}$, M G JAMADAR ${ }^{1}$, ASHOK M PATIL ${ }^{3}$, SANJIT ANAND ${ }^{2}$ \\ ${ }^{1}$ Department of Pharmacology, Al Ameen Medical College, Vijayapur, Karnataka, India. ${ }^{2}$ Department of Pharmacology, K.S. Hegde Medical \\ Academy, NITTE University, Mangalore - 575 018, Karnataka, India. ${ }^{3}$ Department of Pathology, Al Ameen Medical College, Vijayapur, \\ Karnataka, India. Email: narendar.kumar23@gmail.com \\ Received: 23 June 2016, Revised and Accepted: 29 June 2016
}

\section{ABSTRACT}

Objective: This study was undertaken to evaluate the preventive effect of heartwood of $P$. marsupium in dexamethasone-induced hyperinsulinemia and hyperglycemia and compare it with that of pioglitazone.

Methods: Male albino wistar rats were divided into five groups ( $\mathrm{n}=6)$. Plain control group received gum acacia (2\%) orally from $\mathrm{d} 1$ to $\mathrm{d} 12$. Dexa control group received gum acacia (2\%) orally for d 1 to $\mathrm{d} 12$ and Dexa ( $8 \mathrm{mg} / \mathrm{kg}$ ) intraperitoneal (i.p.) from $\mathrm{d} 7$ to $\mathrm{d} 12$, during the study period. Two test groups received ethanolic extract of Pterocarpus marsupium heartwood (PME) (1 and $2 \mathrm{~g} / \mathrm{kg} /$ ) per oral (P0), and standard control group received pioglitazone $(60 \mathrm{mg} / \mathrm{kg} / \mathrm{PO})$ from $\mathrm{d} 1$ to $\mathrm{d} 12$. During the 12 -d study period, the two test groups and standard control group received Dexa ( $8 \mathrm{mg} / \mathrm{kg} / \mathrm{i} . \mathrm{p}$.) from $\mathrm{d} 7$ to $\mathrm{d} 12$. On last day of the study, the blood samples were collected by retro-orbital sinus punctureand used for estimation of serum insulin and glucose levels. Homeostatic Model Assessment (HOMA) method was employed to calculate the degree of insulin resistance(IR). Results were analyzed by using one-way analysis of variance followed by Scheffe's multiple comparison test ( $<<0.05$ ).

Results: Treatment with ethanolic extract of $P$. marsupium and pioglitazone significantly $(\mathrm{p}<0.05)$ reduced the elevated insulin and glucose levels as well as HOMA-IR and HOMA-IS values in dexa treated animals.

Conclusion: Ethanolic extract of $P$. marsupium heartwood effectively countered dexamethasone-induced hyperinsulinemia and hyperglycemia. Insulin-sensitizing activity of $P$. marsupium heartwood was found to be more effective than pioglitazone.

Keywords: Pterocarpus marsupium, Insulin resistance, Hyperinsulinemia, Hyperglycemia.

(C) 2016 The Authors. Published by Innovare Academic Sciences Pvt Ltd. This is an open access article under the CC BY license (http://creativecommons. org/licenses/by/4. 0/) DOI: http://dx.doi.org/10.22159/ajpcr.2016.v9s2.13592

\section{INTRODUCTION}

Diabetes mellitus is a global disease estimated to affect around 438 million people by 2030 [1]. Insulin resistance (IR) plays a major role in the pathogenesis of diabetes, obesity, and cardiovascular diseases. It develops many of the consequences associated with metabolic syndrome [2]. Psychological stress and sedentariness occurred due to changes in modern life style which led to a pandemic of metabolic syndrome. The psychological stress and sedentariness occurred due to changes in modern life style which led to a pandemic of metabolic syndrome. Glucocorticoids (GCs) may play a major role in conditions of stress [3]. Excess GCs may trigger the development of IR and elevation of blood glucose levels [4]. Adaptive response from the $\beta$-cells of the pancreas leading to hyperinsulinemia prevents hyperglycemia initially. However, further increase in IR causes relative insulin deficiency and hyperglycemia. GCs promote lipolysis in peripheral tissues which, in turn, increases free fatty acids and glycerol. The excess of fatty acids and glycerol accumulates in the liver and peripheral tissues as fat, involved in pathological abnormalities $[5,6]$.

The homeostatic model assessment (HOMA), developed by Matthews et al., has been commonly employed to quantify the IR in research. This method is most convenient, and easy technique compared to the euglycemic clamp method [7].

Many medicinal herbs have been proved to be efficacious with fewer side effects in the diabetes treatment. Although synthetic drugs are effective, adverse effects are minimizing the use of these drugs in the treatment of diabetes mellitus [8].

Pterocarpus marsupium is a deciduous tree, commonly known as Bijasal or Indian Kino tree, belongs to the family Fabaceae. It possesses different properties such as antioxidant, analgesic, hepatoprotective, antifungal activity, and anti-inflammatory activity [9]. The heartwood of this tree is a medicinally important part having various flavonoids which may be responsible for the anti diabetic effect of this plant [10]. However, insulin-sensitizing activity of P. marsupium is not yet studied in steroid-induced IR in vivo. This study will be useful to identify the more potent drug to counteract the Dexa induced diabetic complications in clinical therapies. Therefore, the present study was aimed to explore the insulin-sensitizing effect of $P$. marsupium and compare with that of pioglitazone in dexamethasone-induced IR in Wistar rats.

\section{METHODS}

Animals

The study was done using male albino Wistar rats weighing around 250-300 g. Permission was obtained from the Institutional Animal Ethics Committee (Reference: KSHEMA/IAEC/02/2013) before the study. As per the regulations of Committee for the Purpose of Control and Supervision on experimental animals, animals were accommodated under standard conditions, at temperature $(23 \pm 2)^{\circ} \mathrm{C}$, humidity $50 \pm 5 \%, 12: 12 \mathrm{hrs}$ lightdark cycles. They were kept in polypropylene cages, rat pellets (Hindustan Lever Limited, Mumbai) and water were given ad-libitum.

\section{Drugs and chemicals}

A purified form of pioglitazone was obtained from Mahalakshmi Chemicals, Hyderabad. Dexamethasone injection was procured from Zydus Pharmaceuticals, Mumbai. Ketamine injection was collected from Neon Laboratories Limited, Mumbai, India. The serum glucose levels were estimated by commercially available kits. Measurement of serum insulin levels was done using ultrasensitive rat insulin enzyme-linked immunosorbent assay (ELISA) kit obtained from Gen X Bio Health Sciences Private Limited, New Delhi. 
Collection and identification of plant material

Heartwood part of P. marsupium was obtained from S.D.M Ayurveda College, Udupi, Karnataka. The material has been identified and authenticated by Dr. Sunil Kumar KN, Senior Research Officer, Department of Pharmacognosy, SDM Centre for Research in Ayurveda and Allied Sciences, Udupi.

\section{Preparation of the ethanolic extract of $\boldsymbol{P}$. marsupium heartwood}

The heartwood material was weighed accurately $(1.8 \mathrm{~kg})$ in a round bottom flask. About $16 \mathrm{~L}$ of absolute ethanol was added to it and allowed to stand for $24 \mathrm{hrs}$. The contents were filtered, and the extract was concentrated by distillation and solvent was removed by evaporation on a water bath. It was completely dried under vacuum. Finally, around $94 \mathrm{~g}$ of dried extract was obtained.

\section{Phytochemical analysis}

Ethanolic extract of $P$. marsupium was subjected to preliminary phytochemical analysis for identification of chemical constituents such as alkaloids, steroids, carbohydrates, tannins, flavonoids, resins, saponins, triterpenoids, and phenols [11].

\section{Experimental design}

Male albino wistar rats were divided into 5 groups of 6 animals in each group. Study was conducted for a period of $12 \mathrm{~d}$. In this study, Group 1 served as plain control which received gum acacia (2\% per oral[PO]/12d) and Group 2 as Dexa control which received vehicle for $12 \mathrm{~d}$ and Dexa (8 mg/kg/intra-peritoneal[i.p.]) from $7^{\text {th }} \mathrm{d}$ to $12^{\text {th }}$ $\mathrm{d}$ during the study period. Rats in group 3 and 4 were treated with graded doses of ethanolic extract of P. marsupium heartwood (PME) 1 and $2 \mathrm{~g} / \mathrm{kg} / \mathrm{PO}$ for $12 \mathrm{~d}$ respectively. Rats in group 5 were treated with a standard drug, pioglitazone $60 \mathrm{mg} / \mathrm{kg} / \mathrm{p} .0$ for $12 \mathrm{~d}$ (PIO60mg/kg). All the groups except the control group received dexamethasone $(8 \mathrm{mg} /$ $\mathrm{kg} /$ i.p.) from $7^{\text {th }} \mathrm{d}$ to $12^{\text {th }} \mathrm{d}$ (Table 1 ). On the last day of the study period, fasting blood was collected by retro-orbital sinus puncture. Blood samples were centrifuged at 2000RPM for 20 minutes, and serum was separated and utilized for the estimation of glucose and insulin levels.

\section{Estimation of biochemical parameters}

Serum glucose levels (mg/dl) were measured by glucose oxidase and peroxidase method [12]. Serum insulin levels $(\mu \mathrm{U} / \mathrm{ml})$ were estimated by ELISA method [13]

\section{HOMA}

The HOMA-IR and HOMA-insulin sensitivity (IS) were used to determine the degree of hepatic IR and IS, respectively [14].

HOMA-IR $=($ Fasting glucose $[\mathrm{mg} / \mathrm{dl}] \times$ fasting insulin $[\mu \mathrm{U} / \mathrm{ml}]) / 405$

HOMA-IS $=10,000 /($ fasting insulin $[\mu \mathrm{U} / \mathrm{ml}] \times$ fasting glucose $[\mathrm{mg} / \mathrm{dl}])$

\section{Statistical analysis}

The data were presented in mean \pm standard error of the mean. Results were analyzed by one-way analysis of variance followed by Scheffe's multiple comparison post hoc test using SPSS software. Level of significance was assumed at $5 \%$, and $\mathrm{p}<0.05$ was considered as statistically significant.

\section{RESULTS}

\section{Phytochemical analysis}

The phytochemical investigations of PME revealed the presence of alkaloids, flavonoids, resins, steroids, phenols, and triterpenoids (Table 2).

\section{Fasting serum insulin and glucose levels}

Dexamethasone administration to Wistar rats showed significant $(\mathrm{p}<0.05)$ increase in serum insulin and glucose levels compared to control group. Treatment with PME (1 and $2 \mathrm{~g} / \mathrm{kg}$ ) and pioglitazone $60 \mathrm{mg} / \mathrm{kg}$ significantly $(\mathrm{p}<0.05)$ reduced serum insulin and glucose levels compared to dexa control group. There was a significant $(\mathrm{p}<0.05)$
Table 1: Grouping of animals

\begin{tabular}{ll}
\hline Groups & Treatments \\
\hline Group 1-Plain control & Gum acacia (2\%) oral (vehicle) \\
Group 2-Dexa control & Vehicle+dexamethasone $8 \mathrm{mg} / \mathrm{kg} / \mathrm{i} . \mathrm{p}$. \\
Group 3-PME 1 g/kg & Ethanolic extract of P. marsupium \\
& $1 \mathrm{~g} / \mathrm{kg} /$ oral+dexa $8 \mathrm{mg} / \mathrm{kg} / \mathrm{i} . \mathrm{p}$. \\
Group 4-PME $2 \mathrm{~g} / \mathrm{kg}$ & Ethanolic extract of $P$ marsupium \\
& $2 \mathrm{~g} / \mathrm{kg} /$ oral+dexa $8 \mathrm{mg} / \mathrm{kg} / \mathrm{i} . \mathrm{p}$. \\
Group 5-PIO $60 \mathrm{mg} / \mathrm{kg}$ & Pioglitazone $60 \mathrm{mg} / \mathrm{kg} / \mathrm{oral}+$ dexa \\
& $8 \mathrm{mg} / \mathrm{kg} / \mathrm{i} . \mathrm{p}$. \\
\hline
\end{tabular}

P. marsupium: Pterocarpus marsupium

Table 2: Phytochemical constituents in PME extract

\begin{tabular}{ll}
\hline Test & Present (+)/absent (-) \\
\hline Alkaloids & + \\
Carbohydrates & - \\
Flavonoids & + \\
Resins & + \\
Phenols & + \\
Triterpenoids & + \\
Steroids & + \\
Coumarins & - \\
Carboxylic acids & - \\
Quinones & - \\
Saponins & - \\
Tannins & - \\
Amino acids & - \\
\hline
\end{tabular}

PME: Ethanolic extract of Pterocarpus marsupium

difference observed between PME1g/kg and PIO60mg/kg treated groups in terms of reduction in insulin and glucose levels. However, there was no significant ( $p>0.05$ ) difference between PI060mg/kg and PIO 60 mg/kg groups (Table 3 and Fig. 1).

\section{HOMA-IR and HOMA-IS}

HOMA of IR and IS was used to estimate IR and IS, respectively. Dexa control group showed a significant rise in HOMA-IR and decreased in HOMA-IS compared to plain control group $(\mathrm{p}<0.05)$. Treatment with two doses of PME (1 and $2 \mathrm{~g} / \mathrm{kg}$ ) and PI060 mg/kg had shown significant fall in IR and rise in IS compared over dexa control group $(p<0.05)$. There was a significant difference between the mean values of HOMA-IR and IS $(\mathrm{p}<0.05)$ in PME1g/ $\mathrm{kg}$ and PIO60mg/kg treated groups. However, an insignificant difference was seen between PME1g/kg and PIO60mg/kg treated groups in HOMA-IR ( $\mathrm{p}>0.05)$. However, the difference in mean values of HOMA-IS was significant in between these two groups $(\mathrm{p}<0.05)$ (Table 3$)$.

\section{DISCUSSION}

Insulin is an anabolic hormone which plays a major role in the uptake of glucose in peripheral tissues [15]. But, GCs impair insulin signaling in peripheral tissues which lead to IR [16]. Dexamethasone is a potent synthetic steroid selected for the present study to induce IR [17]. Our study indicates that intraperitoneal administration of dexamethasone for six d significantly induced IR. It was proved by the rise in serum glucose and insulin levels as well as increase in HOMA-IR and decrease in HOMA-IS values of dexa treated rats. Dexamethasone by impairing insulin signaling, it reduces insulin sensitivity and causes hyperinsulinemia and hyperglycemia [18,19]. The underlying mechanism of dexamethasone to induce IR might be due to inhibition of glucose uptake by antagonizing translocation of glucose transporters to the plasma membrane [20-22]. It enhances gluconeogenesis and also causes down regulation of insulin receptors [23].

The synthetic groups of drugs such as biguanides, thiazolidinediones, and glucagon-like peptide-1 (GLP 1) mimetics have proved their benefit in GC-induced IR syndrome [24-26]. However, certain adverse effects 
Table 3: Antidiabetic activity of PME extract

\begin{tabular}{|c|c|c|c|c|c|}
\hline Parameter & Plain control & Dexa 8 mg/kg & PME $1 \mathrm{~g} / \mathrm{kg}$ & PME 2 g/kg & PIO 60 mg/kg \\
\hline Fasting glucose (mg/dl) & $101.18 \pm 0.97$ & $268.23 \pm 2.13^{* a, c, d, e}$ & $158.23 \pm 5.41^{*, \mathrm{~b}, \mathrm{e}}$ & $125.19 \pm 1.95^{*, \mathrm{~b}}$ & $135.21 \pm 1.91^{*, \mathrm{~b}, \mathrm{c}}$ \\
\hline Fasting insulin $(\mu \mathrm{U} / \mathrm{ml})$ & $67.48 \pm 2.28$ & $438.4 \pm 8.74 * a, c, d, e$ & $214.16 \pm 9.53^{*, \mathrm{~b}, \mathrm{e}}$ & $129.92 \pm 7.81^{*, \mathrm{~b}}$ & $150.24 \pm 7.88^{*, \mathrm{~b}, \mathrm{c}}$ \\
\hline HOMA-IR & $16.88 \pm 0.72$ & $290.38 \pm 6.53^{* a, c, d, e}$ & $83.73 \pm 4.81^{*, \mathrm{~b}, \mathrm{e}}$ & $40.06 \pm 2.18^{*, \mathrm{~b}}$ & $50.10 \pm 2.47^{*, \mathrm{~b}, \mathrm{c}}$ \\
\hline HOMA-IS & $1.47 \pm 0.06$ & $0.09 \pm 0.001^{* a, c, d, e}$ & $0.30 \pm 0.01^{*, \mathrm{~b}, \mathrm{e}}$ & $0.63 \pm 0.36^{*, \mathrm{~b}, \mathrm{e}}$ & $0.49 \pm 0.03^{*, \mathrm{~b}, \mathrm{c}, \mathrm{d}}$ \\
\hline
\end{tabular}

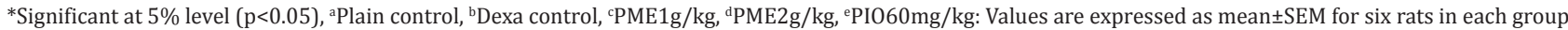
$(\mathrm{n}=6)$. SEM: Standard error of mean, HOMA: Homeostatic model assessment, IR: Insulin resistance, IS: Insulin sensitivity, PME: Ethanolic extract of Pterocarpus marsupium, PIO: Pioglitazone

limit their use in the treatment of IR. Metformin though effective causes gastrointestinal adverse effects and lactic acidosis [27]. Glitazones as a group are hepatotoxic, cardiotoxic, and also there is an increased incidence of bladder cancer [28,29]. GLP-1 mimetics can cause thyroid carcinoma [30]. These factors necessitate the need for new compounds with better safety profile.

P. marsupium has been used in Ayurvedic medicine for the treatment of diabetes mellitus. It has a high amount of polyphenolic compounds [31] In the present study, phytochemical analysis of heartwood of PME revealed the presence of phenols, flavonoids, terpenoids, alkaloids, resins, and steroids (Table 2). Several studies reported that flavonoids, terpenoids, and phenols are considered as effective antidiabetic principles and produce synergistic activity in diabetes [32,33].

Early detection and prevention of IR may reduce the risk of the development of diabetes and other disturbances of metabolic syndrome [34]. Our study confirmed that the treatment with PME extract led to effective prevention of IR induced by dexamethasone. It was reflected by a significant reduction in serum insulin and glucose levels in rats treated with PME extract compared to PIO60mg/kg treated group (Table 3). The possible insulin-sensitizing activity of heartwood of PME extract might be due to the stimulation of glucose uptake into the skeletal muscles as described by Mishra et al. [35] Phenolic compounds of $P$. marsupium heartwood like marsupin and pterostilbene may play a major role in improving glycemic control, and in turn, IR induced by dexamethasone [36]. It was also reported that the flavonoid constituents of P. marsupium heartwood could upregulate the peroxisome proliferator's activator receptor- $\Upsilon$ gene expression, and in turn, the glucose metabolism by decreasing cytokine tumor necrosis factor- $\alpha$ levels [37].

The HOMA index was used to measure the IR and IS in all study groups. This calculation is one of the useful tools to measure the degree of insulin resistance [38]. This calculation is one of the useful tools to measure the degree of insulin resistance [38]. In the present study, dexamethasonetreated animals revealed a state of IR and decreased IS. This was indicated by the increase in HOMA-IR and decrease in HOMA-IS values compared to control group (Table 3). The elevated values of HOMA-IR with dexamethasone were effectively prevented by both doses of PME extract (1, $2 \mathrm{~g} / \mathrm{kg}$ ) and PIO60 $\mathrm{mg} / \mathrm{kg}$ treatment. However, treatment with PME $2 \mathrm{~g} / \mathrm{kg}$ exhibited superiority over PIO60 $\mathrm{mg} / \mathrm{kg}$ in the improvement of HOMA-IS, which suggests that PME2 $\mathrm{g} / \mathrm{kg}$ is most effective in the treatment of IR compared to PIO60mg/kg (Table 3). These effects were in correlation with the insulin and glucose levels. Overall, the insulinsensitizing activity of PME extract is thought to be synergistic effects of various phytochemical compounds present in the drug.

\section{CONCLUSION}

It is concluded that the heartwood of $P$. marsupium has more effective insulin-sensitizing property compared with that of pioglitazone. Further studies are required to identify the active chemical compounds, which are responsible for the insulin-sensitizing property.

\section{ACKNOWLEDGMENT}

We are grateful to Dr. B. Satheesh Kumar Bhandary, Dean, K. S. Hegde Medical Academy, NITTE University, Mangalore, for his kind cooperation to carry out research work. We also thank Dr. Rajendra Holla, Professor and Head of Pharmacology, Dr. Sucheta Shetty, Professor of Biochemistry and Members of Central Research Laboratory, K. S. Hegde Medical Academy, NITTE University, Mangalore, for their support in carrying research work.

\section{REFERENCES}

1. Sushma D, Randhir S. Antidiabetic activity of methanolic extract of Nepeta hindostana herb in streptozotocin induced diabetes in rats. Int $\mathrm{J}$ Pharm Sci 2016;8(7):330-5.

2. Rao G. Insulin resistance syndrome. Am Fam Physician 2001;63(6):1159-63, 1165-6.

3. Macfarlane DP, Forbes S, Walker BR. Glucocorticoids and fatty acid metabolism in humans: Fuelling fat redistribution in the metabolic syndrome. J Endocrinol 2008;197(2):189-204.

4. Brotman DJ, Girod JP, Garcia MJ, Patel JV, Gupta M, Posch A, et al. Effects of short-term glucocorticoids on cardiovascular biomarkers. J Clin Endocrinol Metab 2005;90(6):3202-8.

5. Innes KE, Vincent HK, Taylor AG. Chronic stress and insulin resistance-related indices of cardiovascular disease risk, Part I: Neurophysiological responses and pathological sequelae. Altern Ther Health Med 2007;13(4):46-52.

6. Schneiter P, Tappy L. Kinetics of dexamethasone-induced alterations of glucose metabolism in healthy humans. Am J Physiol 1998;275:E806-13.

7. Matthews DR, Hosker JP, Rudenski AS, Naylor BA, Treacher DF, Turner RC. Homeostasis model assessment: Insulin resistance and betacell function from fasting plasma glucose and insulin concentrations in man. Diabetologia 1985;28(7):412-9.

8. Kadam JS, Pati RN. Effect of Aloe vera leaf extract on alloxan induced diabetes in young mice. Int J Pharm Clin Res 2016;8(6):561-4.

9. Bala Chandra PS, Rajitha B, Anusha CH, Nagasirisha M, Chetty CM, Mohamed Saleem TS. Pterocarpus marsupium Roxb. A potent herb for life threatening diseases. Int J Phytochem Pharmacol 2012;2(2):75-83.

10. Patil UH, Dattatraya KG. Pterocarpus marsupium: A valuable medicinal plant in diabetes management. Int J Appl Biol Pharm Technol 2011;2(3):6-13.

11. Khandelwal KR. Techniques and experiments. Practical Pharmacognosy. Vol. 9. Pune: Nirali Prakashan; 2008. p. 15.

12. Trinder P. Determination of blood glucose using an oxidaseperoxidase system with a non-carcinogenic chromogen. J Clin Pathol 1969;22(2):158-61.

13. Babu KS, Nagendra N, Hebbal GV. Hypoglycemic effect of alcohol extract of Eugenia jambolana seed against dexamethasone induced diabetes in rats. Int J Med Health Sci 2015;4(1):77-81.

14. Baset MA, Osama MA, Lobna AA, Margit S. Maternal rat diabetes mellitus deleteriously affects insulin sensitivity and beta-cell function in the offspring. J Diabetes Res 2013. Available from: http://www. dx.doi.org/10.1155/2013/429154.

15. Pandey N, Pathak RK, Sharma NR. Comparison of commercially available drugs for Type 2 diabetes with natural molecule from Tinospora. Int J Pharm Sci 2016;8(7):173-5.

16. Rafacho A, Marroqui L, Taboga SR, Abrantes JL, Silveira LR, Boschero AC, et al. Glucocorticoids in vivo induce both insulin hypersecretion and enhanced glucose sensitivity of stimulus-secretion coupling in isolated rat islets. Endocrinology 2010;151(1):85-95.

17. Sakoda H, Ogihara T, Anai M, Funaki M, Inukai K, Katagiri H, et al. Dexamethasone-induced insulin resistance in 3T3-L1 adipocytes is due to inhibition of glucose transport rather than insulin signal transduction. Diabetes 2000;49(10):1700-8.

18. Nicod N, Giusti V, Besse C, Tappy L. Metabolic adaptations to dexamethasone-induced insulin resistance in healthy volunteers. Obes Res 2003;11(5):625-31. 
19. Rafacho A, Cestari TM, Taboga SR, Boschero AC, Bosqueiro JR. High doses of dexamethasone induce increased beta-cell proliferation in pancreatic rat islets. Am J Physiol Endocrinol Metab 2009;296(4):E681-9.

20. Oda N, Nakai A, Mokuno T, Sawai Y, Nishida Y, Mano T, et al. Dexamethasone induced changes in glucose transporter 4 in rat heart muscle, skeletal muscle and adipocytes. Eur $\mathrm{J}$ Endocrinol 1995;133(1):121-6.

21. Choi SB, Jang JS, Hong SM, Jun DW, Park S. Exercise and dexamethasone oppositely modulate beta-cell function and survival via independent pathways in $90 \%$ pancreatectomized rats. J Endocrinol 2006;190(2):471-82.

22. Ohneda M, Johnson JH, Inman LR, Unger RH. GLUT-2 function in glucose-unresponsive beta cells of dexamethasone-induced diabetes in rats. J Clin Invest 1993;92(4):1950-6.

23. Derakhshanian H, Djalali M, Djazayery A, Golpaie A, Ekhlasi G. Quercetin improves postprandial hyperglycemia in rats treated with high-dose glucocorticoid. Pharmacol Online 2012;2:93-7.

24. Rojas LB, Gomes MB. Metformin: An old but still the best treatment for type 2 diabetes. Diabetol Metab Syndr 2013;5(1):6

25. Ding SY, Shen ZF, Chen YT, Sun SJ, Liu Q, Xie MZ. Pioglitazone can ameliorate insulin resistance in low-dose streptozotocin and high sucrose-fat diet induced obese rats. Acta Pharmacol Sin 2005;26(5):575-80.

26. Gupta V. Glucagon-like peptide-1 analogues: An overview. Indian J Endocrinol Metab 2013;17(3):413-21.

27. Aksay E, Yanturali S, Bayram B, Hocaolu N, Kiyan S. A rare side effect of metformin: Metformin induced hepatotoxicity. Turk J Med Sci 2007;37(3):173-5.

28. Desouza CV, Shivaswamy V. Pioglitazone in the treatment of Type 2 diabetes: Safety and efficacy review. Clin Med Insights Endocrino
Diabetes 2010;3:43-51

29. Piccinni C, Motola D, Marchesini G, Poluzzi E. Assessing the association of pioglitazone use and bladder cancer through drug adverse event reporting. Diabetes Care 2011;34(6):1369-71.

30. Chiu WY, Shih SR, Tseng CH. A review on the association between glucagon-like peptide-1 receptor agonists and thyroid cancer. Exp Diabetes Res 2012;2012:924168.

31. Gairola S, Gupta V, Singh B, Maithani M. Phytochemistry and pharmacological activities of Pterocarpus marsupium - A review. Int Res J Pharm 2010;1(1):100-4.

32. Atta-Ur-Rahman, Zaman K. Medicinal plants with hypoglycemic activity. J Ethnopharmacol 1989;26(1):1-55

33. Maruthupandian A, Mohan VR. Antidiabetic, antihyperlipidaemic and antioxidant activity of Pterocarpus marsupium Roxb. In alloxan induced diabetic rats. Int J PharmTech Res 2011;3(3):1681-7.

34. Singh B, Saxena A. Surrogate markers of insulin resistance: A review World J Diabetes 2010;1(2):36-47.

35. Mishra A, Srivastava R, Srivastava SP, Gautam S, Tamrakar AK, Maurya R, et al. Antidiabetic activity of heartwood of Pterocarpus marsupium Roxb. And analysis of phytoconstituents. Indian J Exp Biol 2013;51(5):363-74

36. Manickam M, Ramanathan M, Jahromi MA, Chansouria JP, Ray AB Antihyperglycemic activity of phenolics from Pterocarpus marsupium. J Nat Prod 1997;60(6):609-10.

37. Halagappa K, Girish HN, Srinivasan BP. The study of aqueous extract of Pterocarpus marsupium Roxb. On cytokine TNF-a in Type 2 diabetic rats. Indian J Pharmacol 2010;42(6):392-6.

38. Qu HQ, Li Q, Rentfro AR, Fisher-Hock SP, McCormick JB. The definition of insulin resistance using HOMA-IR for Americans of Mexican descent using machine learning. PLoS One 2011;6(6):e21041. 